\title{
An Integrated Field and Hyperspectral Remote Sensing Method for the Estimation of Pigments Content of Stipa Purpurea in Shenzha, Tibet
}

\author{
Bo Kong, ${ }^{1}$ Bing He, ${ }^{1}$ Huan Yu, ${ }^{2}$ and $\mathrm{Yu} \mathrm{Liu}^{2}$ \\ ${ }^{1}$ Institute of Mountain Hazards and Environment, Chinese Academy of Sciences, Chengdu 610041, China \\ ${ }^{2}$ College of Earth Sciences, Chengdu University of Technology, Chengdu 610059, China \\ Correspondence should be addressed to Bing He; hebing@imde.ac.cn
}

Received 28 November 2016; Revised 20 March 2017; Accepted 7 May 2017; Published 22 June 2017

Academic Editor: Huade Guan

Copyright (C) 2017 Bo Kong et al. This is an open access article distributed under the Creative Commons Attribution License, which permits unrestricted use, distribution, and reproduction in any medium, provided the original work is properly cited.

\begin{abstract}
Stipa purpurea is the representative type of alpine grassland in Tibet and the surviving and development material for herdsmen. This paper takes Shenzha County as the research area. Based on the analysis of typical hyperspectral variables sensitive to chlorophyll content of Stipa purpurea, 10 spectral variables with significant correlation with chlorophyll were extracted. The estimation model of chlorophyll was established. The photosynthetic pigment contents in the Shenzha area were calculated by using HJ-1A remote sensing images. The results show that (1) there are significant correlations between chlorophyll content and spectral variables; in particular, the coefficient of Chlb in Stipa purpurea with RVI is the largest (0.728); (2) 10 variables are correlated with chlorophyll, and the order of correlation is Chlb > Chla > Chls; (3) for the estimation of Chla, the EVI is the best variable. RVI, NDVI, and VI2 are suitable for Chlb; RVI and NDVI are also suitable for the estimation of Chls; (4) the mean estimated content of Chla in Stipa bungeana is about 4.88 times that of Chlb, while Cars is slightly more than Chlb; (5) the distribution of Chla is opposite to Chlb and Chls content in water area.
\end{abstract}

\section{Introduction}

Stipa purpurea, distributed in northern Tibet, is the most important and largest ecological system and the survival and development materials for herdsmen $[1,2]$. At the same time, Stipa purpurea grassland known as alpine biological germplasm resources has unique species diversity and high biodiversity conservation value. Due to the severe natural conditions in northern Tibet, the ecological system of Stipa purpurea grassland is extremely fragile and the antidisturbance ability is poor $[3,4]$. Once the grassland vegetation is destroyed, it is difficult to recover. Photosynthetic pigment content, as an effective plant health indicator for the detection of photosynthesis and disease pollution $[5,6]$, can be estimated and analyzed by remote sensing. This will be useful not only for analyzing the growth and health status of Stipa purpurea grassland, but also for reflecting the succession of Stipa purpurea community. It could play an important role in regulating and improving the environment of Qinghai-Tibet plateau or even the whole Eurasia.

The nutritional status of plants is closely related to pigment content and compositions in vegetation biochemical parameters. Chlorophyll is such kind of vegetation biochemical parameter and closely related to nitrogen, protein, water, and others. When the grassland is damaged, the chlorophyll content will be reduced, which can indirectly reflect the physiological condition of the grassland under external stress. Chlorophyll can absorb light and convert it into electrical energy, while carotenoid has the function of preventing chlorophyll photooxidation besides collecting and transmitting light energy [7]. The traditional quadratic survey of chlorophyll has some shortcomings such as sparse sampling points and measurement difficulties in large scale, which leads to low reliability of analysis results. The hyperspectral remote sensing provides the possibility for estimating photosynthetic pigment contents in grassland $[8,9]$ and 
is important for the estimating of photosynthetic capacity, species identification, production dynamic observation, and precision fertilization $[10,11]$.

At present, hyperspectral remote sensing has made progress in monitoring vegetation pigment contents, and some hyperspectral chlorophyll indices have been proposed by maximizing the reflection information of vegetation and minimizing the influence of external factors (e.g., aerosol, soil background, and nonphotosynthetic materials) [12-20]. For example, Horler et al. [12] studied the relationship between vegetation spectrum and chlorophyll content and analyzed the role of red edge position (wavelength of vegetation derivative spectrum near $700 \mathrm{~nm}$ ) for the assessment of chlorophyll concentration. The contents of biochemical components (chlorophyll, lignin, nitrogen, cellulose, etc.) of 12 kinds of leaves were computed by using the firstorder derivative reflectance spectroscopy and absorption characteristics method. Blackburn [15] proposed two new indices for estimating the pigment concentrations of four deciduous broad-leaved species at different wilting stages by using a simple ratio of specific pigment simple index and a normalized difference index of specific pigments. Richardson et al. [17] used traditional extraction techniques to measure chlorophyll a (Chla), chlorophyll b (Chlb), and total chlorophyll content (Chls) of 100 paper birch leaves and found that some indices based on reflectance, such as the chlorophyll NDI, were much better indicators of chlorophyll content than some of the more commonly used indices, such as $\lambda$ RE or NDVI. Dash and Curran [18] proposed a new index called the MERIS terrestrial chlorophyll index (MTCI) using data in three red/NIR wavebands centered at 681.25, 708.75, and $753.75 \mathrm{~nm}$, and the MTCI appeared to be a most suitable index for the estimation of chlorophyll content with Medium Resolution Imaging Spectrometer (MERIS) data. The MERIS index is now a standard level-2 product of European Space Agency.

The above-mentioned indices can be classified into four types [21], single spectral index, normalized spectral index, ratio spectral index, and multiband spectral index, and can obtain very fine vegetation physiological conditions and environmental stress differences by their unique fine spectral characteristics. But, the majority of hyperspectral chlorophyll indices were developed for crops [22] or forests other than grassland [23]. Nichol and Grace [24] found that several previously published indices performed relatively poorly and yielded low coefficients, and some ecologically important species remain to be explored, despite their "applicability" across many species types [25]. Especially in alpine grassland, the hyperspectral estimation model for pigment content of Stipa purpurea community is rarely reported.

The objectives of this paper are (1) to take the sparse grass group of Stipa purpurea community as the target in alpine grassland and analyze its canopy and community spectral characteristics; (2) to extract spectral information and establish the correlation with pigments content; and (3) to analyze the spatial distribution of pigments content of Stipa purpurea in Shenzha. The remainder of this paper describes the field experiment, spectral analysis, and characteristics and the Stipa purpurea mapping results. The specific methods

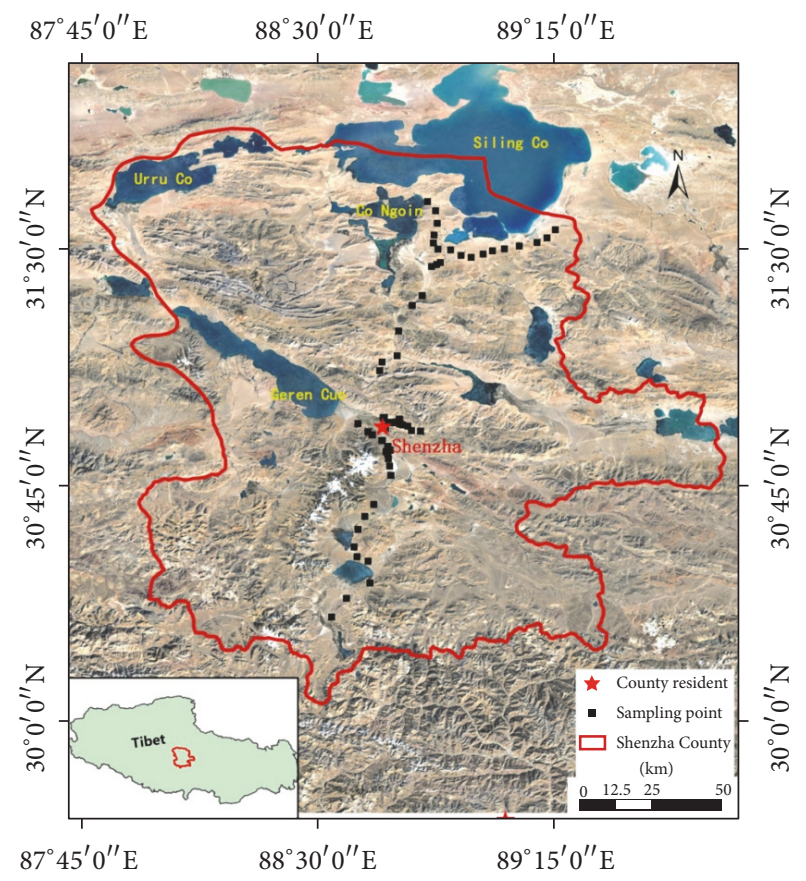

FIGURE 1: The study area and schematic plot of sample point.

are as follows: (1) the hyperspectral characteristic variables were selected by spectral analysis, and the spectral data were processed by statistical method; (2) correlation analysis was carried out and the sensitive parameters were selected to establish the pigments content and spectral characteristics of the estimation model; (3) in order to reflect the distribution and succession of Stipa purpurea community, the maps are produced and analyzed by GIS tools.

\section{Materials and Methods}

2.1. Study Area. Shenzha County is located in the middle of Tibet, southwest of Naqu area. The average elevation of this area is $4750 \mathrm{~m}$. The annual average temperature is below $0^{\circ} \mathrm{C}$, and the highest temperature is $10^{\circ} \mathrm{C}$ every year in July-August. The minimum temperature is $-40^{\circ} \mathrm{C}$. The Stipa purpurea grassland is well developed in Shenzha, and it is widely distributed in slopes, hills, rivers, and lakes terraces and lake plains, which are well drained below $4900 \mathrm{~m}$, forming a large grassland community. This region has vast grassland and abundant water resources, which is one of the traditional pastoral areas in Tibet. As a result of long-term overgrazing, some good grasslands have been significantly degraded, such as Stellera chamaejasme Linn, Morina kokonorica Hao, and other poisonous grass.

2.2. Spectral Data Acquisition. The selection of quadratic sampling location is very important for field spectrum acquisition process. The selected target must be representative and can truly reflect the average characteristics. In this paper, the field experiment locations are shown in Figure 1. Each location is a typical Stipa purpurea community in northern Tibet plateau of Shenzha. A total of 9 sampled plots 

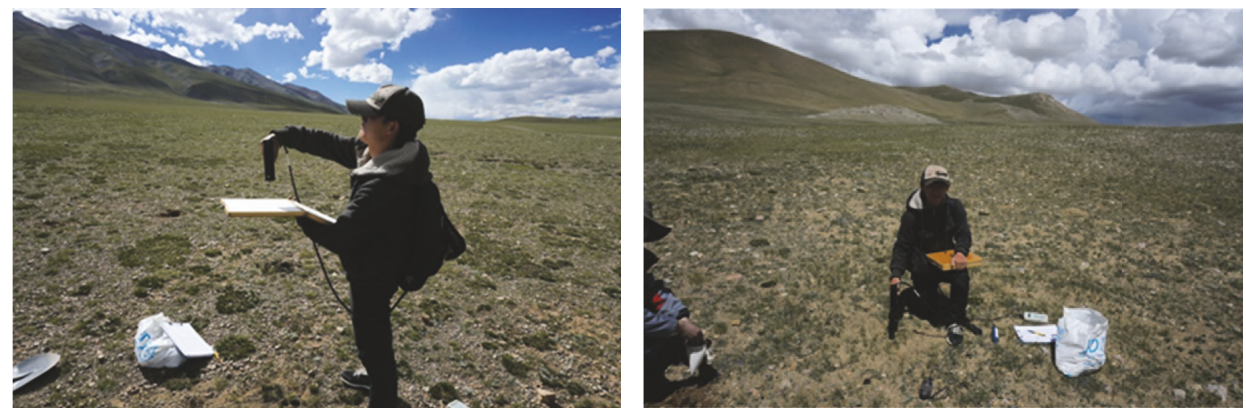

FIgURE 2: Field experiment.

$(0.5 \mathrm{~m} \times 0.5 \mathrm{~m})$ were selected randomly, and 60 test units were measured. The spectral reflectance of Stipa purpurea was measured by SVC HR-1024 portable spectrometer. The spectral range of this spectrometer is from $350 \mathrm{~nm}$ to $2500 \mathrm{~nm}$ and the number of channels is 1024. In order to show the best growth status of alpine grassland, field experiments are seasoned between August and September 2015, which is the growth season of Stipa purpurea community in Shenza area. The weather is sunny, without wind or with very little wind. The measurement time is controlled between 11:00 and 14:00. In the measurement, a single vegetation type was selected. The sensor head of spectrometer is down vertically, the field angle is $4^{\circ}$, the height of the grass canopy is about $20 \mathrm{~cm}$, the coverage is nearly $100 \%$, and the diameter is about $5.2 \mathrm{~cm}$. Four sampling points were selected randomly in each plot for spectral determination, and the mean value was taken as the repeat spectral reflectance value. In order to reduce the impact of atmospheric changes, plots and reference whiteboard was measured alternately (as shown in Figure 2). At each sample point, GPS, grass height, and coverage were recorded at the same time.

2.3. Remote Sensing Data and Its Preprocessing. The HJ-1A hyperspectral imager (HSI) product was downloaded from July to August 2015 from China Centre for Resources Satellite Data and Application, with ground width of $50 \mathrm{~km}$, spatial resolution of $100 \mathrm{~m}$, and 128 bands ranging from $450 \mathrm{~nm}$ to $950 \mathrm{~nm}$. The hyperspectral data was selected according to the growing season of Stipa purpurea in study area. The principle of data selection is to remove the image covering the same area with a larger sampling time or poor quality, thus reducing the error caused by mismatch between the ground sampling and satellite monitoring time. Finally, 46 images were selected; 13 images contain quadratic samples. And then these images were postprocessed such as band fusion, geometric correction, and projection conversion.

2.4. Determination of Photosynthetic Pigments. In order to extract photosynthetic pigments of alpine grassland, the optical density was measured by spectrophotometry at the wavelength of $663 \mathrm{~nm}, 647 \mathrm{~nm}, 537 \mathrm{~nm}$, and $470 \mathrm{~nm}$. According to Lambert-Beer law, The Chla, Chlb, Chls, and Carotenoids (Cars) were calculated. Each process was repeated three times, and the average value was taken as the photosynthetic pigment content. A total of 70 samples were determined, and four photosynthetic pigment contents were determined for each sample.

$$
\begin{aligned}
& \text { Chla }=0.137 A_{663}-0.000897 A_{537}-0.003046 A_{647}, \\
& \text { Chlb }=0.024 A_{647}-0.004305 A_{537}-0.005507 A_{663}, \\
& \text { Chls }=\text { Chla }+ \text { Chlb, } \\
& \text { Cars } \\
& =\frac{\left(A_{470}-\left(17.1 \times\left(\mathrm{Chl}_{\mathrm{a}}+\mathrm{Chl}_{\mathrm{b}}\right)-9.479 \times \text { Anthocyanin }\right)\right)}{119.26}, \\
& \text { Anthocyanin }=0.0817 A_{537}-0.00697 A_{647}-0.002228 A_{663} .
\end{aligned}
$$

2.5. Feature Parameter Extraction of Hyperspectral Data. In order to explore the characteristics of canopy reflectance spectrum of Stipa purpurea, some useful narrow bands were selected from hyperspectral bands for remote sensing information extraction. The aboveground biomass was modeled by using hyperspectral data and various transformations, such as red, yellow, and blue optical parameters, vegetation index, green reflection peak, and red light absorption valley. The spectral data of the experimental units were smoothed and deaveraged four times. The parameters such as the position, area, vegetation index, and derivative of the spectra were calculated (as shown in Table 1). The linear and nonlinear regression equations were established by comparing these spectral variables with the light and pigment contents, and the optimal estimation model of one or more variables was preliminarily screened.

2.6. Regression Method. A stepwise regression analysis method was used to determine the biomass-related spectral variable equation, and the measured biomass and spectral variable value was then input. The output result was a series of multivariate linear equations containing different spectral variables, as well as the corresponding determination coefficient $\left(R^{2}\right)$, and test value $(F)$. The stepwise regression model was as follows:

$$
Y=a_{0}+a_{1} x_{1}+a_{2} x_{2}+\cdots+a_{i} x_{i}+\cdots,
$$

where $x_{i}$ is the spectral variable value; $Y$ is the biomass estimation value; $a_{0}$ is a constant item; and $a_{i}$ represents the partial regression coefficient. 
TABLE 1: High spectral characteristic parameter selection.

\begin{tabular}{|c|c|c|c|c|}
\hline Types & Name & Abbreviation & Calculation formula & Literature \\
\hline \multirow{9}{*}{$\begin{array}{l}\text { Spectral area and } \\
\text { location } \\
\text { parameters }\end{array}$} & Blue margin value & $D_{\mathrm{b}}$ & $\begin{array}{l}\text { Maximum of first derivative spectrum in } 490 \text { to } \\
520 \mathrm{~nm} \text { wavelength }\end{array}$ & Elvidge et al., 1995 \\
\hline & Blue margin area & $\mathrm{SD}_{\mathrm{b}}$ & $\begin{array}{l}\text { Integration of first derivative in } 490 \text { to } 520 \mathrm{~nm} \\
\text { wavelength }\end{array}$ & Elvidge et al., 1995 \\
\hline & Yellow margin value & $D_{\mathrm{y}}$ & $\begin{array}{l}\text { Maximum of first derivative spectrum in } 560 \text { to } \\
\qquad 640 \mathrm{~nm} \text { wavelength }\end{array}$ & Elvidge et al., 1995 \\
\hline & Yellow margin area & $\mathrm{SD}_{\mathrm{y}}$ & $\begin{array}{l}\text { Integration of first derivative in } 560 \text { to } 640 \mathrm{~nm} \\
\text { wavelength }\end{array}$ & Elvidge et al., 1995 \\
\hline & Red margin value & $D_{\mathrm{r}}$ & $\begin{array}{l}\text { Maximum of first derivative spectrum in } 670 \text { to } \\
\qquad 760 \mathrm{~nm} \text { wavelength }\end{array}$ & Elvidge et al., 1995 \\
\hline & Red margin area & $\mathrm{SD}_{\mathrm{r}}$ & $\begin{array}{l}\text { Integration of first derivative in } 670 \text { to } 760 \mathrm{~nm} \\
\text { wavelength }\end{array}$ & Pu et al., 1993 \\
\hline & Green peak reflectance & $R_{\mathrm{g}}$ & $\begin{array}{c}\text { Maximum of band reflectance in } 520 \text { to } 560 \mathrm{~nm} \\
\text { wavelength }\end{array}$ & Elvidge et al., 1995 \\
\hline & Green peak area & $\mathrm{SD}_{\mathrm{g}}$ & $\begin{array}{c}\text { Area of original spectrum in } 520 \text { to } 560 \mathrm{~nm} \\
\text { wavelength }\end{array}$ & Elvidge et al., 1995 \\
\hline & Red valley reflectance & $R_{\mathrm{r}}$ & $\begin{array}{l}\text { Minimum of band reflectance in } 650 \text { to } 690 \mathrm{~nm} \\
\text { wavelength }\end{array}$ & Elvidge et al., 1995 \\
\hline \multirow{3}{*}{$\begin{array}{l}\text { Ratio parameters } \\
\text { of spectral area } \\
\text { and location }\end{array}$} & $\begin{array}{l}\text { Ratio between green peak } \\
\text { reflectance and red valley } \\
\text { reflectance }\end{array}$ & VI1 & $\frac{\rho_{\mathrm{g}}}{\rho_{\mathrm{r}}}$ & Gitelson et al., 1996 \\
\hline & $\begin{array}{l}\text { Normalization value of green } \\
\text { peak reflectance and red valley } \\
\text { reflectance }\end{array}$ & VI2 & $\frac{\rho_{\mathrm{g}}-\rho_{\mathrm{r}}}{\rho_{\mathrm{g}}+\rho_{\mathrm{r}}}$ & Gitelson et al., 1996 \\
\hline & $\begin{array}{l}\text { Ratio between red margin area } \\
\text { and blue margin area }\end{array}$ & VI3 & $\frac{\mathrm{SD}_{\mathrm{r}}}{\mathrm{SD}_{\mathrm{b}}}$ & Gitelson et al., 2003 \\
\hline \multirow{4}{*}{$\begin{array}{l}\text { Vegetation } \\
\text { indices }\end{array}$} & Ratio vegetation index & RVI & $\frac{\rho_{\mathrm{NIR}}}{\rho_{\mathrm{Re} d}}$ & Jordan, 1969 \\
\hline & $\begin{array}{l}\text { Normalized difference vegetation } \\
\text { index }\end{array}$ & NDVI & $\frac{\rho_{\mathrm{NIR}}-\rho_{\mathrm{Re} d}}{\rho_{\mathrm{NIR}}+\rho_{\mathrm{Re} d}}$ & Rouse, 1973 \\
\hline & Enhanced vegetation index & EVI & $\frac{\rho_{\mathrm{NIR}}-\rho_{\mathrm{Re} d}}{\rho_{\mathrm{NIR}}+C_{1} \rho_{\mathrm{Re} d}-C_{2} \rho_{\mathrm{B}}+L}(1+L)$ & Liu, 1995 \\
\hline & $\begin{array}{l}\text { Again normalized difference } \\
\text { vegetation index }\end{array}$ & RDVI & $\sqrt{\mathrm{NDVI} \times\left(\rho_{\mathrm{NIR}}-\rho_{\mathrm{Re} d}\right)}$ & Richardson, 1992 \\
\hline
\end{tabular}

\section{Results and Analysis}

3.1. Hyperspectral Analysis of Stipa Purpurea. Grassland vegetation, atmosphere, water, soil, and other factors form a comprehensive reflection spectrum of grassland. The reflectance is affected by many factors, such as grassland population, type, vegetation water content, vegetation coverage, air condition, and soil condition. Therefore, the spectrum analysis of Stipa purpurea is the basis of remote sensing monitoring of forage resources in Tibetan plateau, and its spectral characteristics are the integrated responses of Stipa purpurea and its habitat conditions.

It can be seen from Figure 3 that the overall trend of 5 different coverages of Stipa purpurea samples is consistent, although the spectral reflectance is varying. The blueband with the largest water penetration is located in the chlorophyll absorption zone of green plants between 490 and $520 \mathrm{~nm}$. It shows that blue-band is sensitive to the chlorophyll concentration and is helpful for the identification of plant

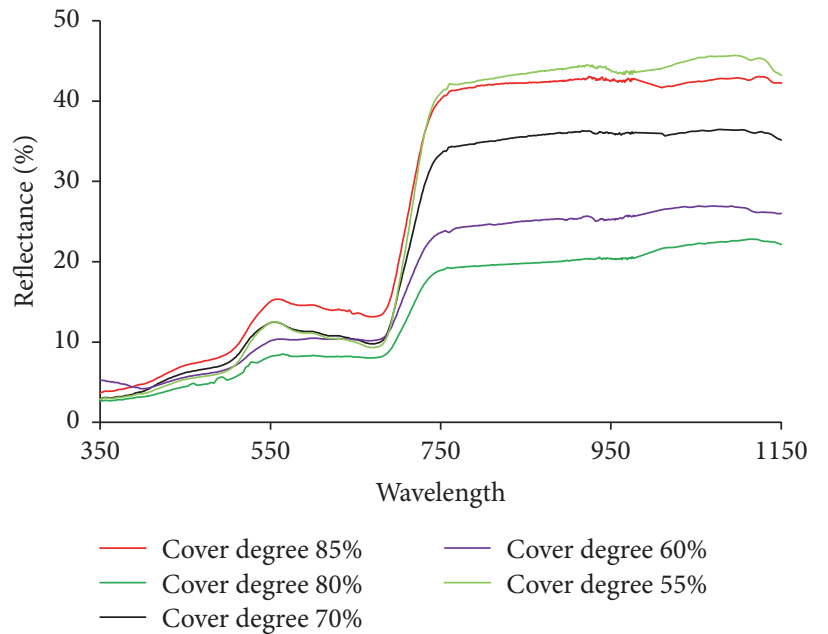

FIGURE 3: Comparison of different coverage of Stipa purpurea spectral reflectance curve. 
TABLE 2: The correlation coefficient of Stipa pigment content and spectral variables.

\begin{tabular}{lccccc}
\hline & $\begin{array}{c}\text { Characteristic } \\
\text { variables }\end{array}$ & Chla & Chlb & Chls & Cars \\
\hline \multirow{4}{*}{ Spectral } & $D_{\mathrm{b}}$ & $-.409^{*}$ & $-.407^{*}$ & $-.377^{*}$ & -0.007 \\
location & $D_{\mathrm{y}}$ & -0.016 & -0.007 & -0.038 & -0.157 \\
variable & $D_{\mathrm{r}}$ & $-.424^{*}$ & $-.398^{*}$ & $-.417^{*}$ & 0.015 \\
& $R_{\mathrm{g}}$ & $-.579^{* *}$ & $-.578^{* *}$ & $-.556^{* *}$ & -0.053 \\
& $R_{\mathrm{r}}$ & $-.589^{* *}$ & $-.592^{* *}$ & $-.571^{* *}$ & -0.035 \\
\hline \multirow{4}{*}{ Spectral area } & $\mathrm{SD}_{\mathrm{b}}$ & $-0.414^{*}$ & $-.404^{*}$ & $-.395^{*}$ & -0.098 \\
variable & $\mathrm{SD}_{\mathrm{y}}$ & -0.315 & -0.322 & -0.32 & 0.038 \\
& $\mathrm{SD}_{\mathrm{r}}$ & 0.123 & 0.124 & 0.094 & -0.09 \\
& $\mathrm{SD}_{\mathrm{g}}$ & $-.583^{* *}$ & $-.584^{* *}$ & $-.561^{* *}$ & -0.06 \\
\hline \multirow{3}{*}{ Vegetation } & $\mathrm{RVI}$ & $.707^{* *}$ & $.728^{* *}$ & $.694^{* *}$ & 0.14 \\
variable & $\mathrm{NDVI}$ & $.594^{* *}$ & $.607^{* *}$ & $.571^{* *}$ & 0.026 \\
& $\mathrm{EVI}$ & $.606^{* *}$ & $.623^{* *}$ & $.584^{* *}$ & 0.075 \\
& $\mathrm{RDVI}$ & $.661^{* *}$ & $.679^{* *}$ & $.644^{* *}$ & 0.09 \\
\hline \multirow{3}{*}{ VI variable } & $\mathrm{VI1}$ & $.597^{* *}$ & $.627^{* *}$ & $.609^{* *}$ & 0.131 \\
& $\mathrm{VI} 2$ & $.569^{* *}$ & $.594^{* *}$ & $.578^{* *}$ & 0.104 \\
& $\mathrm{VI3}$ & $.626^{* *}$ & $.630^{* *}$ & $.585^{* *}$ & 0.045 \\
\hline
\end{tabular}

Note. $*$ and $* *$ indicate significant levels at 0.05 and 0.01 , respectively.

stress. This conclusion is consistent with Jin et al.s research [26]. The green reflectance of healthy grass between 490 and $520 \mathrm{~nm}$ is sensitive to grass reflectance, and it could be used to identify grassland type and plant productivity state. At the same time, the green band reflection peaks also increase with the lift of coverage and growth conditions. The sharp rising portion between the red and the near-infrared bands of high reflectance is located in the vicinity of the red edge of $700-750 \mathrm{~nm}$. In the decreasing process of coverage, the red edge of the spectrum will shift to the long wave direction, and the offset is about $10 \sim 40 \mathrm{~nm}$. The near-infrared band is located in the meadow high reflection area $(760-900 \mathrm{~nm})$. The spectral characteristics are controlled by the cell structure of the grassland and are sensitive to the change of the grassland type, density, and growth force. The higher the vegetation height, the coverage, and the productivity, the higher the reflectance is. The canopy reflectance is usually between $20 \%$ and $40 \%$, which is due to the multiple reflection and scattering of the internal tissue structure of plant leaves and is mainly determined by biomass and leaf area index.

3.2. Data Analysis. The hyperspectral data after transformation were correlated with pigments content and the results are shown in Table 2. There are significant correlations between chlorophyll content and spectral characteristic variables; in particular, the correlation coefficient of chlorophyll content with green peak reflectance, red valley reflectance, green peak area, RVI, NDVI, EVI, RDVI, VI1, VI2, and VI3 reached 0.01 significant level. The correlation coefficient of Chlb of Stipa purpurea and RVI is the largest value of 0.728 . The correlation coefficient of Chla, Chlb, and Chls to RVI, EVI, RDVI, and VI3 is 0.6. The correlation coefficient between carotenoid content and 16 characteristic variables is generally low, which indicates that the spectral characteristic variables of Stipa purpurea are correlated with chlorophyll, and the chlorophyll content could be estimated by using the characteristic variables with good correlation.

3.3. Model Construction and Verification. In many studies, hyperspectral remote sensing data is used to estimate the chlorophyll content. The main method was to find the bands relation to chlorophyll content by regression method. In high spectral narrow band data, the green band uses $553 \mathrm{~nm}$ reflectivity, the red band uses $670 \mathrm{~nm}$ reflectivity, the near-infrared band uses $801 \mathrm{~nm}$ reflectivity to carry on the inversion parameter operation, and the result is valid. This is due to the fact that $553 \mathrm{~nm}$ and $670 \mathrm{~nm}$ are used to determine the most responsive narrow band position according to $R_{\mathrm{g}}$, $R_{\mathrm{r}}$ two parameters; $801 \mathrm{~nm}$ is used to screen out the narrow band at near-infrared band according to many experts in the grassland vegetation index parameters [26]. The regression models of chlorophyll and band combination are shown in Table 3.

Based on the analysis of typical hyperspectral variables sensitive to chlorophyll content of Stipa purpurea, 10 variables with significant correlation with chlorophyll were extracted in Table 3, and SPSS22.0 was used to analyze Chla, Chlb, and Chls. We analyzed the linear, quadratic, logarithmic, and exponential models and selected the higher coefficient of determination of Chla and Chlb and total chlorophyll as the basis for the modeling of Stipa purpurea (as shown in Figure 4). The observed data were randomly selected and divided into two groups: one for the training samples $(n=30)$ is used to establish the regression relationship.

As shown in Table 4, all the regression equations $R^{2}$ are tested by 0.01 significance and varied between 0.623 and 0.708 with an average value of 0.658 . For the Chla content estimation, the best fitting model is EVI variable parabola equation, $R^{2}$ is $0.708, F$-test value is 31.9 , and the estimated standard error is small; for Chlb, the best fitting model is the parabolic equation of RVI, NDVI, and VI2 variables, the $F$ test value is large, and the standard error is small. For the estimation of Chls, the best fitting model is also the parabolic equation of RVI and NDVI, $R^{2}$ value is 0.644 , and $F$ test value reached 12.79 .

3.4. Spatial Pattern Analysis. The best models for Chla, $\mathrm{Chlb}$, and Chls estimation were obtained and validated by correlation coefficient model (as shown in Table 3, Figure 4). The hyperspectral raster data can be directly used to calculate the spatial results. In the calculation process, the green band uses $553 \mathrm{~nm}$ reflectivity which is 38 band of HJ-1A image, $670 \mathrm{~nm}$ reflectivity as red band which is 70 band of HJ$1 \mathrm{~A}$ image, and $801 \mathrm{~nm}$ reflectivity as the near-infrared band. Finally, EVI parameters of Chla, RVI value of Chlb, and EVI parameters of Chls were calculated and substituted into the estimation model, respectively. The photosynthetic pigment contents in Shenzha area were estimated by HJ-1A images.

The contents of Chla, Chlb, and Chls in Shenzha area are shown in Figure 5. The Chla is in the range of $0-30 \mathrm{mg} / \mathrm{g}$. The 
TABLE 3: Estimation model and evaluation index of the photosynthetic pigment content of Stipa purpurea.

\begin{tabular}{|c|c|c|c|c|c|c|}
\hline \multirow{2}{*}{ Variable } & \multirow{2}{*}{ Model } & \multirow{2}{*}{ Model function } & \multicolumn{2}{|c|}{ Training sample $(n=30)$} & \multicolumn{2}{|c|}{ Validation sample $(n=20)$} \\
\hline & & & $R^{2}$ & $F$ & $R^{2}$ & SEE \\
\hline \multirow{3}{*}{$R_{\mathrm{g}}$} & Chla & $y=18.941 e^{-0.101 x}$ & 0.360 & 15.755 & 0.337 & 0.318 \\
\hline & Chlb & $y=4.9395 e^{-0.134 x}$ & 0.421 & 20.358 & 0.400 & 0.734 \\
\hline & Chls & $y=0.0483 x^{2}-2.031 x+24.361$ & 0.402 & 9.086 & 0.358 & 3.226 \\
\hline \multirow{3}{*}{$R_{\mathrm{r}}$} & Chla & $y=0.0498 x^{2}-1.8608 x+20.157$ & 0.522 & 14.737 & 0.486 & 3.415 \\
\hline & Chlb & $y=0.0103 x^{2}-0.4021 x+4.3275$ & 0.430 & 21.154 & 0.410 & 0.950 \\
\hline & Chls & $y=0.0685 x^{2}-2.3681 x+23.633$ & 0.484 & 12.686 & 0.446 & 2.996 \\
\hline \multirow{3}{*}{$\mathrm{SD}_{\mathrm{g}}$} & Chla & $y=3 E-05 x^{2}-0.0524 x+22.071$ & 0.384 & 8.409 & 0.338 & 3.877 \\
\hline & Chlb & $y=19.434 e^{-0.003 x}$ & 0.425 & 20.706 & 0.405 & 0.731 \\
\hline & Chls & $y=4 E-05 x^{2}-0.0554 x+24.53$ & 0.401 & 9.053 & 0.357 & 3.229 \\
\hline \multirow{3}{*}{ RVI } & Chla & $y=0.0087 x^{2}+2.4105 x-1.2277$ & 0.655 & 25.575 & 0.629 & 2.903 \\
\hline & Chlb & $y=0.3113 x^{2}-1.4038 x+2.2996$ & 0.712 & 33.423 & 0.691 & 0.687 \\
\hline & Chls & $y=0.1029 x^{2}-1.1332 x+11.11$ & 0.701 & 29.367 & 0.662 & 1.713 \\
\hline \multirow{3}{*}{ NDVI } & Chla & $y=80.457 x^{2}-55.9 x+13.24$ & 0.686 & 29.554 & 0.663 & 2.766 \\
\hline & Chlb & $y=29.211 x^{2}-21.795 x+4.5795$ & 0.653 & 25.415 & 0.627 & 0.755 \\
\hline & Chls & $y=140.84 x^{2}-110.27 x+24.82$ & 0.612 & 21.281 & 0.583 & 2.600 \\
\hline \multirow{3}{*}{ EVI } & Chla & $y=9.7705 x^{2}-13.358 x+8.1238$ & 0.710 & 32.995 & 0.688 & 0.864 \\
\hline & Chlb & $y=3.5428 x^{2}-5.4181 x+2.6148$ & 0.702 & 31.812 & 0.680 & 0.700 \\
\hline & Chls & $y=20.154 x^{2}-44.399 x+32.094$ & 0.556 & 16.913 & 0.523 & 2.034 \\
\hline \multirow{3}{*}{ RDVI } & Chla & $y=3.2447 x^{2}-1.5165 x+2.8664$ & 0.659 & 26.097 & 0.634 & 2.884 \\
\hline & Chlb & $y=3.114 x^{2}-5.8428 x+3.3762$ & 0.699 & 31.412 & 0.677 & 0.703 \\
\hline & Chls & $y=6 E-06 x^{2}-0.0098 x+11.83$ & 0.655 & 25.682 & 0.630 & 1.792 \\
\hline \multirow{3}{*}{ VI1 } & Chla & $y=7.6192 x^{2}-2.3606 x-1.567$ & 0.579 & 18.593 & 0.525 & 3.285 \\
\hline & Chlb & $y=13.379 x^{2}-27.295 x+14.61$ & 0.583 & 18.839 & 0.552 & 0.828 \\
\hline & Chls & $y=47.726 x^{2}-96.932 x+53.56$ & 0.436 & 10.454 & 0.395 & 3.133 \\
\hline \multirow{3}{*}{$\mathrm{VI} 2$} & Chla & $y=127.15 x^{2}+17.461 x+3.7539$ & 0.589 & 19.320 & 0.558 & 3.167 \\
\hline & Chlb & $y=127.15 x^{2}+17.461 x+3.75$ & 0.589 & 19.349 & 0.559 & 0.822 \\
\hline & Chls & $y=337.33 x^{2}-10.643 x+4.124$ & 0.444 & 10.784 & 0.403 & 3.112 \\
\hline \multirow{3}{*}{ VI3 } & Chla & $y=436.67 x^{2}-617.11 x+220.8$ & 0.668 & 27.196 & 0.644 & 2.877 \\
\hline & Chlb & $y=0.0378 x^{2}-0.3662 x+1.507$ & 0.552 & 16.652 & 0.519 & 0.858 \\
\hline & Chls & $y=0.2864 x^{2}-3.8448 x+17.188$ & 0.549 & 16.415 & 0.515 & 2.804 \\
\hline
\end{tabular}

TABLE 4: Stepwise regression models of photosynthetic pigment in Stipa purpurea with enhanced spectral variables (with VIF $=35, R^{2}$ is the coefficient of determination, $F$ is the value of $F$ distribution, and $P$ is the significant level).

\begin{tabular}{|c|c|c|c|c|}
\hline Soil properties & Regression models & $R^{2}$ & $F$ & $P$ \\
\hline Chla & $y=0.466-9.17 \mathrm{EVI}$ & 0.708 & 31.9 & 0.000 \\
\hline Chlb & $y=12.69+11.22 \mathrm{RVI}-6.57 \mathrm{NDVI}+0.027 \mathrm{VI} 2$ & 0.623 & 48.36 & 0.000 \\
\hline Chls & $y=0.902+0.741 \mathrm{RVI}+1.866 \mathrm{NDVI}$ & 0.644 & 12.79 & 0.000 \\
\hline
\end{tabular}

Chla values in bare soil and alpine steppe region are low, the Siling Co. and Kering Co. are up to $30 \mathrm{mg} / \mathrm{g}$, and the alpine swamp meadow near lake is $18 \mathrm{mg} / \mathrm{g}$. The range of Chlb is $0-15 \mathrm{mg} / \mathrm{g}$. The Chlb values in the alpine swamp meadow and alpine meadow near Kering Co. are $6-10 \mathrm{mg} / \mathrm{g}$ and in the alpine grassland are varied from 10 to $15 \mathrm{mg} / \mathrm{g}$. The Chls is between 7 and $50 \mathrm{mg} / \mathrm{g}$, and its spatial distribution is similar to Chlb. The above results indicate that the distribution of Chla is opposite to Chlb and total chlorophyll. Chlb determines the distribution pattern of Chls in the water area, but the Chlb value is lower than the Chla. The Chls in the wetland is between 15 and $25 \mathrm{mg} / \mathrm{g}$, while the chlorophyll in the alpine steppe and alpine desert steppe is lower than that in the dry soil condition.

3.5. Photosynthetic Pigment Analysis. The Chla and Chlb are the most studied parameters in photosynthetic pigments content. The lutein, carotenoids, and other photosynthetic 

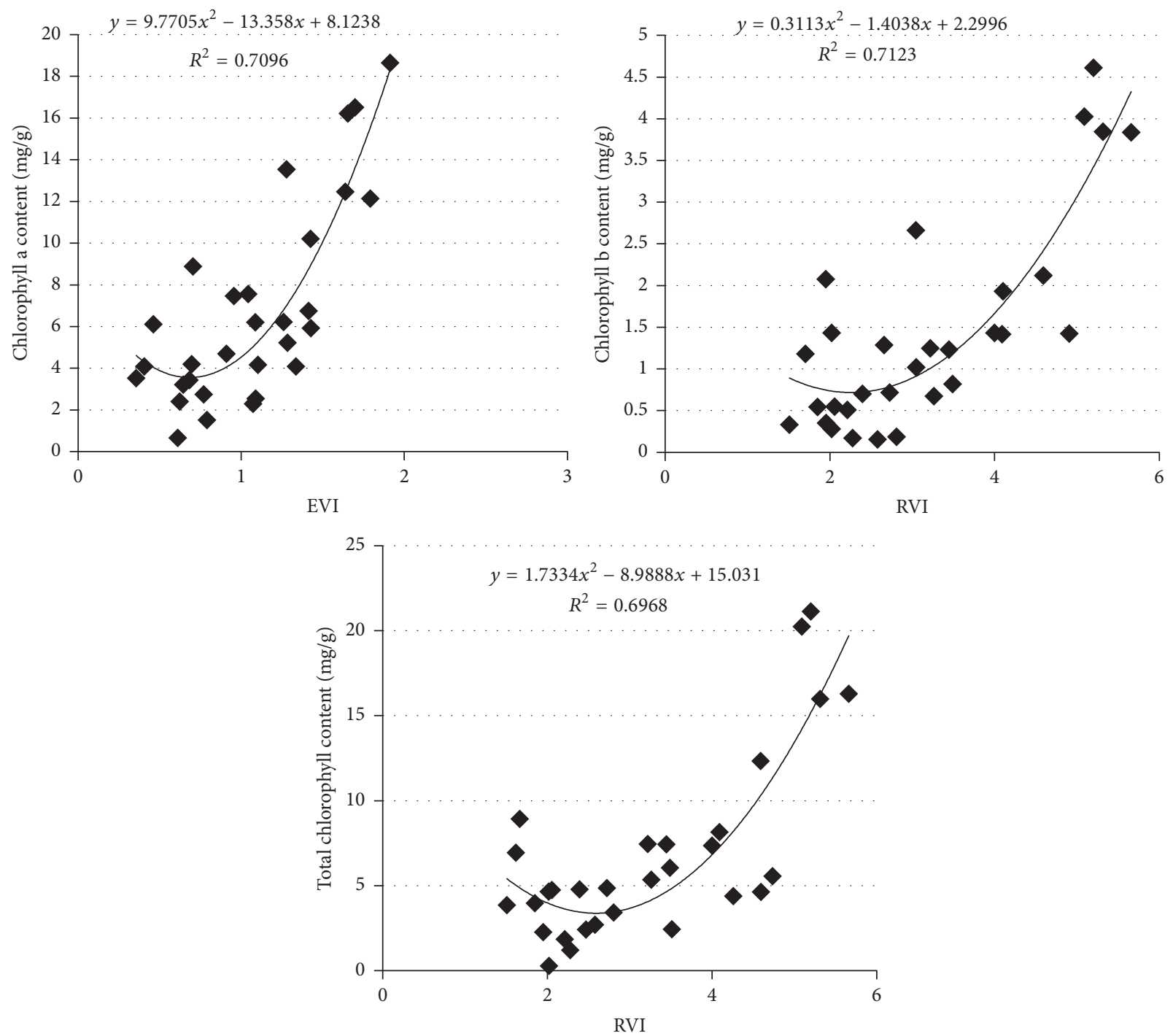

FIGURE 4: Results of the optimal estimation model of the photosynthetic pigment of Stipa purpurea.

TABLE 5: The correlation coefficient between different pigments.

\begin{tabular}{lcccc}
\hline pigment & Chla & Chlb & Chls & Cars \\
\hline Chla & 1 & 0.8597 & 0.9886 & 0.7540 \\
Chlb & 0.8597 & 1 & 0.9266 & 0.5126 \\
Chls & 0.9886 & 0.9266 & 1 & 0.7060 \\
Cars & 0.7540 & 0.5126 & 0.7060 & 1 \\
\hline
\end{tabular}

pigments are not only the composition of light-emitting pigment. Under the external stress they are more involved in the leaves of yellow Cyclin and other metabolic pathways. The correlation coefficients of the pigment content of Stipa grandis were correlated with each other by 0.01 . In particular, the correlation coefficient between the Chla and Chls is 0.98 (Table 5), indicating that the trend of change between different pigments is consistent, and the response of different pigments in the spectral characteristic parameters are similarity (Table 3), such as Chla, Chla, and Chls of RVI.
In single factor model, $R^{2}$ of RVI is higher than 0.65 , and $R_{\mathrm{g}}$ and $\mathrm{SD}_{\mathrm{g}}$ are both lower than 0.42 . It is shown that the characteristic parameters are consistent with the simulation of the photosynthetic pigment content. Some parameters are related to all the pigment correlations, and some are independent. However, in the stepwise regression model, not all parameters with higher correlation with the pigment can iterate into the equation but rather enter the equation in the form of complementary effects. Several similar parameters are excluded from the model operation (Table 4). The spectral parameters of the hyperspectral remote sensing image are calculated by comparing the band of the characteristic parameters involved in the regression model with the band of the hyperspectral image of HJ-1A and then are substituted into the regression model. The results showed the spatial distribution of Chla, Chlb, and Chls (Figure 5).

The chlorophyll content of Shenzha County was calculated by the spatial distribution data of photosynthetic pigments (Table 6). The mean estimated value content of Chla 


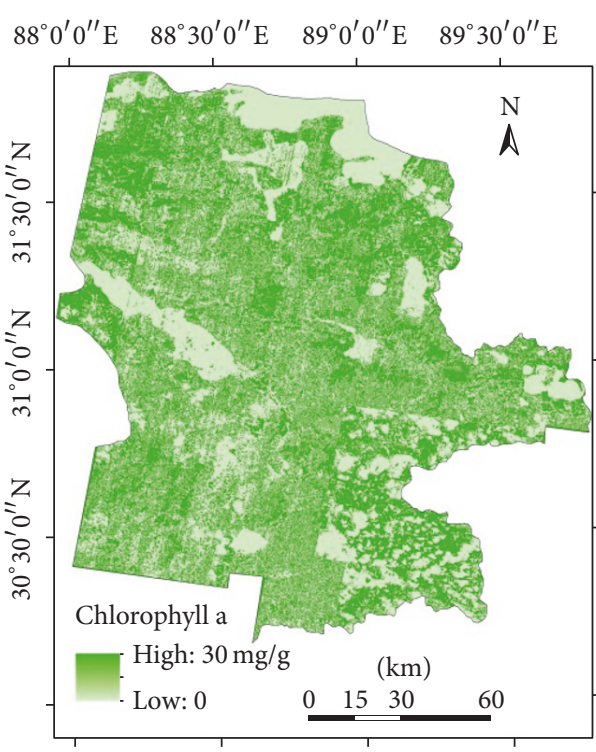

$88^{\circ} 0^{\prime} 0^{\prime \prime} \mathrm{E} \quad 88^{\circ} 30^{\prime} 0^{\prime \prime} \mathrm{E} \quad 89^{\circ} 0^{\prime} 0^{\prime \prime} \mathrm{E} \quad 89^{\circ} 30^{\prime} 0^{\prime \prime} \mathrm{E}$

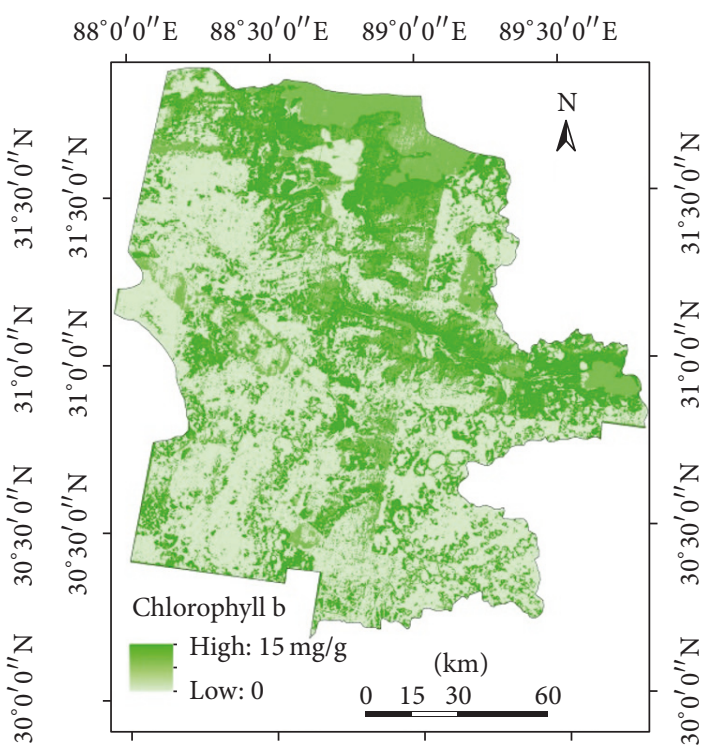

$88^{\circ} 0^{\prime} 0^{\prime \prime} \mathrm{E} \quad 88^{\circ} 30^{\prime} 0^{\prime \prime} \mathrm{E} \quad 89^{\circ} 0^{\prime} 0^{\prime \prime} \mathrm{E} \quad 89^{\circ} 30^{\prime} 0^{\prime \prime} \mathrm{E}$

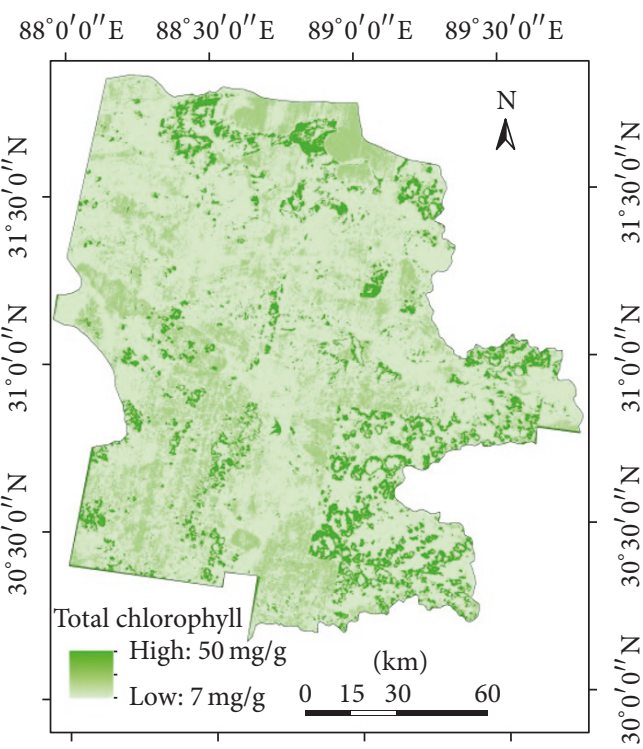

$88^{\circ} 0^{\prime} 0^{\prime \prime} \mathrm{E} \quad 88^{\circ} 30^{\prime} 0^{\prime \prime} \mathrm{E} \quad 89^{\circ} 0^{\prime} 0^{\prime \prime} \mathrm{E} \quad 89^{\circ} 30^{\prime} 0^{\prime \prime} \mathrm{E}$

FIGURE 5: The map of photosynthetic pigment content.

TABLE 6: The chlorophyll content of Shenzha County (mg/g).

\begin{tabular}{lcccccccc}
\hline Pigment & $\begin{array}{c}\text { Maximum } \\
\text { measured } \\
\text { value }\end{array}$ & $\begin{array}{c}\text { Maximum } \\
\text { estimated } \\
\text { value }\end{array}$ & $\begin{array}{c}\text { Minimum } \\
\text { measured } \\
\text { value }\end{array}$ & $\begin{array}{c}\text { Minimum } \\
\text { estimated } \\
\text { value }\end{array}$ & $\begin{array}{c}\text { Average } \\
\text { measured } \\
\text { value }\end{array}$ & $\begin{array}{c}\text { Mean } \\
\text { estimated } \\
\text { value }\end{array}$ & $\begin{array}{c}\text { Estimated } \\
\text { standard } \\
\text { deviation }\end{array}$ & $\begin{array}{c}\text { Relative } \\
\text { error (\%) }\end{array}$ \\
\hline Chla & 31.5 & 29.5 & 1.22 & 0.65 & 10.4 & 9.12 & 7.86 \\
Chlb & 17.2 & 14.9 & 0.40 & 0.01 & 2.50 & 1.87 & 2.07 & 7.24 \\
Chls & 54.6 & 48.5 & 0.96 & 0.29 & 12.8 & 9.23 & 10.7 \\
\hline
\end{tabular}

in Stipa bungeana is about 4.88 times that of Chlb, while Cars is generally slightly more than Chlb, so chlorophyll a plays a dominant role in absorption. The chlorophyll content of the measured sample was slightly higher than that of the spatial estimation, because the change of photosynthetic pigment in the community of Stipa purpurea occurred in the alpine steppe region with low soil water content, and the change of the pigment in the lake and water was small. Some of the images of the snow-covered area (seasonal snow) affect the actual monitoring of photosynthetic pigments, so the estimate is slightly lower, but the estimated relative error is small, below $7.24 \%$. 


\section{Conclusion}

Based on the correlation between ground measured spectral characteristics and photosynthetic pigments, $R_{\mathrm{g}}, R_{\mathrm{r}}, \mathrm{SD}_{\mathrm{g}}$, RVI, NDVI, EVI, RDVI, VI1, VI2, and VI3 characteristic parameters with the correlation level of 0.01 and ground photosynthetic pigments are used to establish single factor equations and select the appropriate spectral characteristic parameters. In these parameters, $R^{2}$ of $R_{\mathrm{g}}, R_{\mathrm{r}}$, and $\mathrm{SD}_{\mathrm{g}}$ are less than 0.42 , so these three parameters do not participate in the next step budget. The three spectral inversion models of Chla, Chlb, and Chls were established by using RVI, NDVI, EVI, RDVI, VI1, VI2, and VI3. Finally, the spatial distribution pattern of Chla, Chlb, and Chls was obtained by using the scale push method and HJ-1A remote sensing image, and the characteristic parameter band in the model was mapped to the band in the hyperspectral remote sensing image. The relative error is small, and the monitoring and investigation of the grassland growth and health status of large-scale area in high altitude and alpine region are realized by using the spatial estimation value and the ground measured value.

(1) In the fitting analysis of pigments content and hyperspectral parameters, $670 \mathrm{~nm}$ is used as the red band, $801 \mathrm{~nm}$ as the near-infrared band, and $553 \mathrm{~nm}$ as the green band to construct pigments content inversion model. Among the 16 spectral parameters, 10 parameters are correlated with chlorophyll, and the correlation order is Chlb $>$ Chla $>$ Chls. The best correlation index between Chla, Chlb, and Chls is RVI, and the correlation coefficients are $0.707,0.728$, and 0.694 , respectively. The results indicate that the estimation of the chlorophyll content of Stipa purpurea is more feasible by using spectral characteristic variables.

(2) The chlorophyll estimation model of Stipa purpurea was established by using 10 extremely significant correlation spectral parameters. The estimation model of Chla is based on vegetation index EVI, estimation of Chlb is based on RVI, NDVI, and VI2, Chls model is based on RVI and NDVI, and the coefficient of determination $\left(R^{2}\right)$ of fitted equation is 0.6. The relative error of the model estimation is small, which is below $7.24 \%$, indicating that the model is feasible in the region.

(3) The distribution of Chla is opposite to Chlb and Chls in the water area. Chlb in water area determines the distribution pattern of Chls, but Chlb value is lower than Chla; thus, the Chls in wetlands near lakes is $15-25 \mathrm{mg} / \mathrm{g}$. The Chls of alpine steppe and alpine desert steppe is mainly affected by Chla in dry soil condition.

(4) The proposed method in this paper can effectively estimate the pigments content of Stipa purpurea in Shenzha, Tibet. The results could reflect the distribution and succession pattern of Stipa purpurea community. However, there are some errors in estimation model for pigment content based on hyperspectral vegetation physiological parameters. This is due to the fact that the vegetation type, growth stage, growth condition, and the signal-to-noise ratio of the spectrometer itself will influence the establishment of statistical model.

\section{Conflicts of Interest}

The authors declare that they have no conflicts of interest.

\section{Acknowledgments}

This research is supported by the National Natural Science Funds of China (41301094); the Hundred Young Talents Program of the Institute of Mountain Hazards and Environment (SDSQB-2015-02); the Lead Strategic Project of the Chinese Academy of Sciences (XDB03030507); the 973 National Projects (2015CB452706); the Open Fund for Spatial Information Technology Key Lab Bases of the Ministry of Land and Resources of China (KLGSIT2014-06).

\section{References}

[1] X. M. Zhou, Q. J. Wang, Y. Q. Zhang, X. Q. Zhao, and Y. P. Lin, "Quantitative analysis of vegetation succession in alpine meadow under different grazing intensity," Journal of Plant Ecology and Botany, vol. 11, no. 4, pp. 276-285, 1987.

[2] M. J. Duan, Q. Z. Gao, Y. F. Wan et al., "Effect of grazing on community characteristics and species diversity of stipa purpurea alpine grassland in northern tibet," Acta Ecologica Sinica, vol. 30, no. 14, pp. 3892-3900, 2010.

[3] D. Lu, Y. Zhao, R. Han, L. Wang, and P. Qin, "The complete chloroplast genome sequence of the Purple Feathergrass Stipa purpurea (Poales: Poaceae)," Conservation Genetics Resources, vol. 8, no. 2, pp. 101-104, 2016.

[4] P. P. Yue, X. F. Lu, R. R. Ye et al., "Distribution of Stipa purpurea steppe in the northeastern qinghai-xizang plateau (China)," Russian Journal of Ecology, vol. 42, no. 1, pp. 50-56, 2011.

[5] D. Filella and J. Peñuelas, "The red edge position and shape as indicators of plant chlorophyll content, biomass and hydric status," International Journal of Remote Sensing, vol. 15, no. 7, pp. 1459-1470, 1994.

[6] A. C. Madeira, A. Mendonça, and M. E. Ferreira, "Relationship between spectroradiometric and chlorophyll measurements in green beans," Communications in Soil Science and Plant Analysis, vol. 31, no. 5-6, pp. 631-643, 2000.

[7] A. A. Gitelson, G. P. Keydan, and M. N. Merzlyak, “Three-band model for noninvasive estimation of chlorophyll, carotenoids, and anthocyanin contents in higher plant leaves," Geophysical Research Letters, vol. 33, no. 11, Article ID L11402, 2006.

[8] M. J. Gallardo, J. P. Staforelli, P. Meza, I. Bordeu, and S. Torres, "Characterization of Chromobacterium violaceum pigment through a hyperspectral imaging system," $A M B$ Express, vol. 4, no. 4, pp. 2-9, 2014.

[9] M. Gupta, P. K. Srivastava, S. Mukherjee, and G. Sandhya Kiran, "Chlorophyll retrieval using ground based hyperspectral data from a tropical area of india using regression algorithms," in Remote Sensing Applications in Environmental Research, vol. 4, pp. 177-194, 2014.

[10] F. Flores-de-Santiago, J. M. Kovacs, and F. Flores-Verdugo, "The influence of seasonality in estimating mangrove leaf 
chlorophyll-a content from hyperspectral data," Wetlands Ecology and Management, vol. 21, no. 3, pp. 193-207, 2013.

[11] D. Haboudane, J. R. Miller, N. Tremblay, P. J. Zarco-Tejada, and L. Dextraze, "Integrated narrow-band vegetation indices for prediction of crop chlorophyll content for application to precision agriculture," Remote Sensing of Environment, vol. 81, no. 2-3, pp. 416-426, 2002.

[12] D. N. H. Horler, J. Barber, and A. R. Barringer, "Effects of heavy metals on the absorbance and reflectance spectra of plants," International Journal of Remote Sensing, vol. 1, no. 2, pp. 121-136, 1980.

[13] A. A. Gitelson, C. Buschmann, and H. K. Lichtenthaler, "The chlorophyll fluorescence ratio F735F700 as an accurate measure of the chlorophyll content in plants," Remote Sensing of Environment, vol. 69, no. 3, pp. 296-302, 1999.

[14] D. A. Sims and J. A. Gamon, "Relationships between leaf pigment content and spectral reflectance across a wide range of species, leaf structures and developmental stages," Remote Sensing of Environment, vol. 81, no. 2-3, pp. 337-354, 2002.

[15] G. A. Blackburn, "Quantifying chlorophylls and carotenoids at leaf and canopy scales: An evaluation of some hyperspectral approaches," Remote Sensing of Environment, vol. 66, no. 3, pp. 273-285, 1998.

[16] J. G. P. W. Clevers and L. Kooistra, "Using hyperspectral remote sensing data for retrieving total canopy chlorophyll and nitrogen content," in Proceedings of 3rd Workshop on Hyperspectral Image and Signal Processing: Evolution in Remote Sensing, WHISPERS 2011, June 2011.

[17] A. D. Richardson, S. P. Duigan, and G. P. Berlyn, "An evaluation of noninvasive methods to estimate foliar chlorophyll content," New Phytologist, vol. 153, no. 1, pp. 185-194, 2002.

[18] J. Dash and P. J. Curran, "Evaluation of the MERIS terrestrial chlorophyll index (MTCI)," Advances in Space Research, vol. 39, no. 1, pp. 100-104, 2007.

[19] J. Delegido, L. Alonso, G. González, and J. Moreno, "Estimating chlorophyll content of crops from hyperspectral data using a normalized area over reflectance curve (NAOC)," International Journal of Applied Earth Observation and Geoinformation, vol. 12, no. 3, pp. 165-174, 2010.

[20] P. Chen, D. Haboudane, N. Tremblay, J. Wang, P. Vigneault, and B. Li, "New spectral indicator assessing the efficiency of crop nitrogen treatment in corn and wheat," Remote Sensing of Environment, vol. 114, no. 9, pp. 1987-1997, 2010.

[21] W. M. Yong and X. M. Wang, "Progress on grassland chlorophyll content estimation by hyperspectral analysis," Progress in Geography, vol. 35, no. 1, pp. 25-34, 2016.

[22] A. Bannari, K. S. Khurshid, K. Staenz, and J. W. Schwarz, "A comparison of hyperspectral chlorophyll indices for wheat crop chlorophyll content estimation using laboratory reflectance measurements," IEEE Transactions on Geoscience and Remote Sensing, vol. 45, no. 10, pp. 3063-3074, 2007.

[23] G. Le Maire, C. François, and E. Dufrêne, “Towards universal broad leaf chlorophyll indices using PROSPECT simulated database and hyperspectral reflectance measurements," Remote Sensing of Environment, vol. 89, no. 1, pp. 1-28, 2004.

[24] C. J. Nichol and J. Grace, "Determination of leaf pigment content in Calluna vulgaris shoots from spectral reflectance," International Journal of Remote Sensing, vol. 31, no. 20, pp. 5409$5422,2010$.

[25] G. L. Jin, J. Z. Zhu, H. L. Liu, S. M. Tang, and C. H. Wang, "Study on physiology/ecology adaptation of main plant in degraded seriphidiumtransiliense desert rangeland," ActaAgrectirSinica, vol. 19, no. 1, pp. 26-30, 2011.

[26] H. A. Jin, D. W. Liu, K. S. Song, Z. M. Wang, F. Li, and H. J. Liu, "Comparing the performance of broad-band and narrowband vegetation indices for estimation of soybean LAI," System Sciences and Comprehensive Studies in Agriculture, vol. 23, no. 4, pp. 503-508, 2007. 


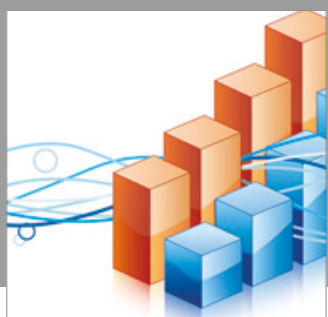

Advances in

Operations Research

vatersals

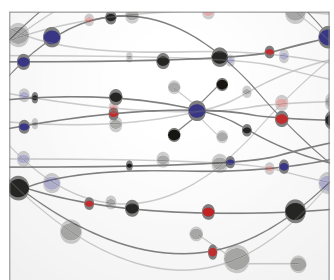

\section{The Scientific} World Journal
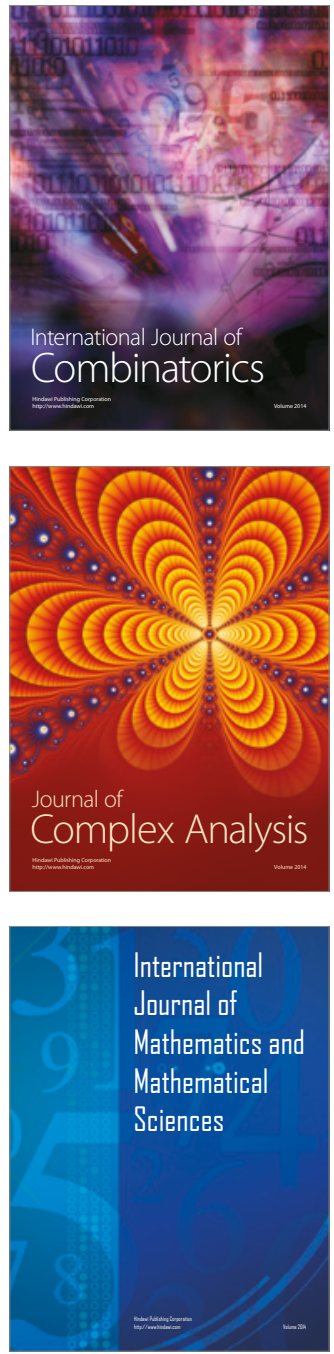
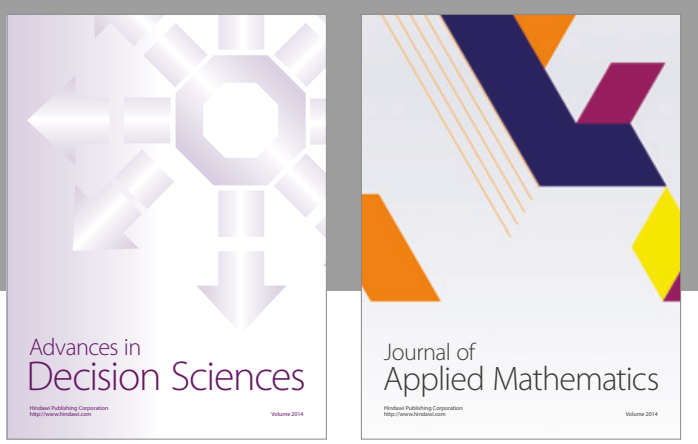

Algebra

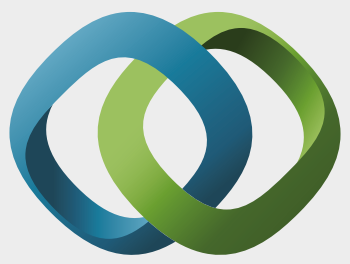

\section{Hindawi}

Submit your manuscripts at

https://www.hindawi.com
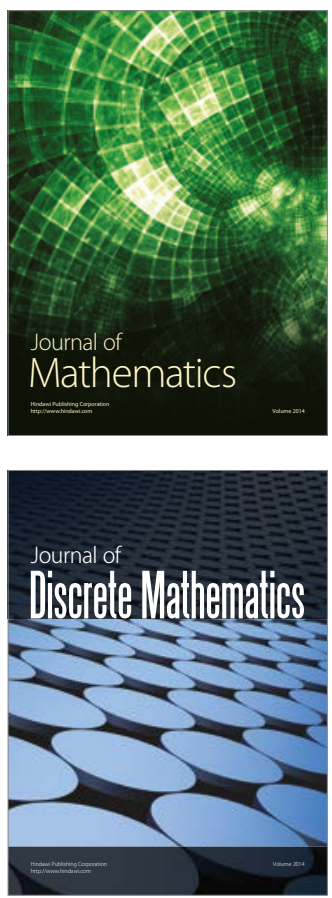

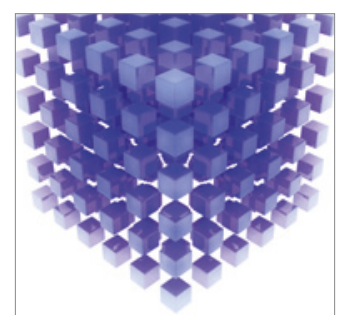

Mathematical Problems in Engineering
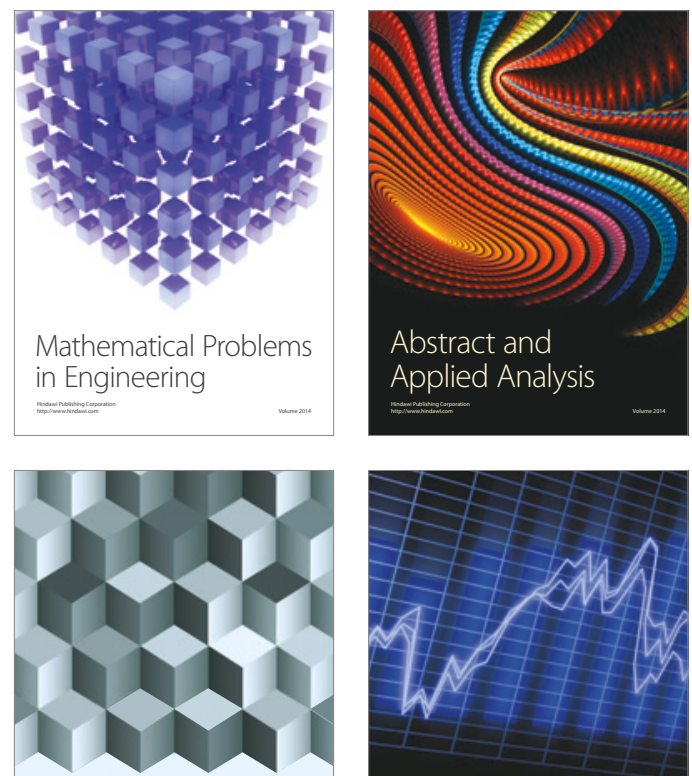

Journal of

Function Spaces

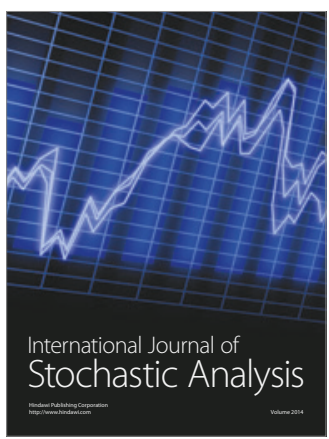

Probability and Statistics
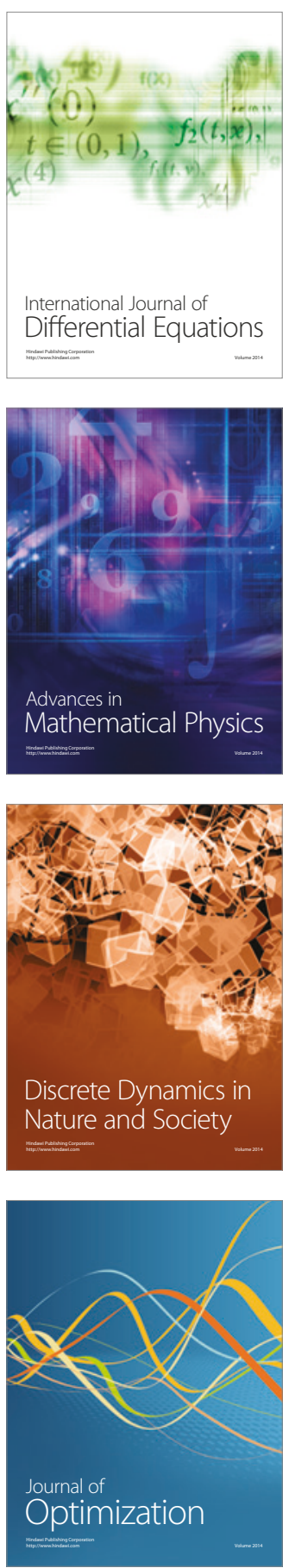